\title{
PEMANFAATAN LEARNING MANAGEMENT SYSTEM (LMS) BERBASIS EDMODO MATERI FLUIDA DINAMIS UNTUK PENINGKATAN MINAT DAN PRESTASI BELAJAR FISIKA SISWA SEKOLAH MENENGAH
}

\author{
Intan Firda Alifiyanti ${ }^{1}$, Finda Hadiatin Afifah ${ }^{2}$, Nurmutmainna Ramadoan ${ }^{3}$ \\ ${ }^{1,2,3}$ Program Studi S2 Pendidikan Fisika, Pascasarjana Universitas Ahmad Dahlan, \\ Jl. Pramuka no 42 Sidikan Umbulharjo, Yogyakarta 55161 \\ Email : ifirdaa21@gmail.com
}

\begin{abstract}
The 2013 curriculum has the policy to reduce and even eliminate homework, so students can use their time at home to study according to their own desires, cooking, farming, art, and other positive activities. The reality shows different things, students use mobile phones, play games, or watch television which causes students to have more difficulty understanding the lesson, lack of interest in learning, practice questions, and improve learning achievement. In fulfilling the additional intake of lessons for students, it is necessary to manage distance learning called the learning management system. This study aims to increase interest and learning achievement using Edmodo as $L M S$. The research subjects were the eleventh-grade student in Ngawi, East Java totaling 31. The study was conducted in October using classroom action research methods. Data collection with observation and questionnaire techniques as qualitative data, as well as student cognitive tests as quantitative data. The results showed that the utilization of Edmodo on fluid dynamics could increase the interest and achievement of physics learning of the eleventh-grade students. Therefore, the utilization of Edmodo needs to be introduced and used by students in the current era digital era.
\end{abstract}

Keywords: LMS, Edmodo, Interest, Achievement

\begin{abstract}
Abstrak: Kurikulum 2013 memiliki kebijakan untuk mengurangi dan bahkan menghilangkan pekerjaan rumah, sehingga siswa dapat menggunakan waktu mereka di rumah untuk belajar sesuai dengan keinginan mereka sendiri, memasak, bertani, seni, dan kegiatan positif lainnya. Kenyataannya menunjukkan hal yang berbeda, siswa menggunakan ponsel, bermain game, atau menonton televisi yang menyebabkan siswa memiliki lebih banyak kesulitan memahami pelajaran, kurangnya minat dalam belajar, latihan soal, dan meningkatkan prestasi belajar. Dalam memenuhi tambahan asupan pelajaran bagi siswa, perlu untuk mengelola pembelajaran jarak jauh yang disebut sistem manajemen pembelajaran. Penelitian ini bertujuan untuk meningkatkan minat dan prestasi belajar menggunakan Edmodo sebagai LMS. Subyek penelitian adalah siswa kelas XI di Ngawi, Jawa Timur sebanyak 31. Penelitian dilakukan pada bulan Oktober menggunakan metode penelitian tindakan kelas. Pengumpulan data dengan teknik observasi dan kuesioner sebagai data kualitatif, serta tes kognitif siswa sebagai data kuantitatif. Hasil penelitian menunjukkan bahwa pemanfaatan Edmodo pada fluida dinamis dapat meningkatkan minat dan prestasi belajar fisika siswa kelas XI. Oleh karena itu, pemanfaatan Edmodo perlu diperkenalkan dan digunakan oleh siswa di era digital era saat ini.
\end{abstract}

Kata kunci: LMS, Edmodo, Minat, Prestasi

\section{PENDAhuluan}

Pendidikan disebutkan sebagai bagian dari 12 pilar daya saing, yaitu sebagai pilar kesehatan dan pendidikan dasar, dan pendidikan tinggi dan pelatihan. 12 pilar daya saing adalah (1) Lembaga (2) Infrastruktur (3) lingkungan ekonomi makro (4) Kesehatan dan 
pendidikan dasar (5) Pendidikan tinggi dan pelatihan (6) efisiensi pasar barang (7) Pasar tenaga kerja efisiensi ukuran pasar (8) pengembangan pasar keuangan, (9) kesiapan teknologi (10) kecanggihan Bisnis (11) dan Inovasi (12), Dua dari dua belas pilar daya saing suatu negara terkait dengan pendidikan di era global abad 21 (Sulisworo, 2016: 130-134). Perhatian utama dari pendidikan dalam pembangunan adalah bagaimana pendidikan dapat menciptakan sumber daya manusia yang mampu memecahkan masalah menghambat daya saing. Alternatif pertama untuk meningkatkan daya saing bangsa adalah strategi meningkatkan kualitas pendidikan itu sendiri. Dampak dari kualitas pendidikan adalah daya saing bangsa, pada dunia pendidikan sumber daya manusia yang baik adalah bagaimana perbaikan sistem pendidikan secara keseluruhan. Strategi meningkatkan kualitas pendidikan salah satunya yaitu peningkatan manajemen pembelajaran dalam kurikulum. Kurikulum yang digunakan saat ini adalah kurikulum 2013 revisi 2018 yang memiliki kebijakan untuk mengurangi bahkan menghapus PR atau pekerjaan rumah siswa dengan harapan siswa dapat menggunakan waktu mereka di rumah untuk belajar sesuai dengan keinginan mereka sendiri, memasak, bertani, seni, dan kegiatan positif lainnya. Kenyataannya menunjukkan hal yang berbeda, siswa lebih banyak menghabiskan waktu di rumah untuk menggunakan ponsel, bermain game, atau menonton televisi yang hal tersebut dapat menyebabkan siswa memiliki banyak kesulitan memahami pelajaran, kurangnya minat dalam belajar, latihan soal, dan meningkatkan prestasi belajar.

Perkembangan teknologi seluler dan bisnisnya menjadi bergerak cepat dalam beberapa tahun terakhir. Biayanya lebih murah dan lebih murah dari sebelumnya dengan peningkatan kapasitas dan kemampuan. Digital teknologi seluler memberikan kemungkinan dan peluang baru untuk perspektif pembelajaran baru, termasuk hubungan antara guru dan siswa (Sulisworo dkk, 2016). Minat pada dasarnya adalah penerimaan akan suatu hubungan antara diri sendiri dengan sesuatu diluar diri sendiri. Semakin kuat atau dekat hubungan tersebut maka dapat diartikan bahwa minat yang dimiliki besar (Slameto, 2010:180). Prestasi belajar adalah perubahan sikap dan tingkah laku setelah menerima pelajaran atau setelah mempelajari sesuatu. prestasi belajar ialah hasil usaha bekerja atau belajar yang menunjukkan ukuran kecakapan yang dicapai dalam bentuk nilai. Sedangkan prestasi belajar hasil usaha belajar yang berupa nilai-nilai sebagai ukuran kecakapan dari usaha belajar yang telah dicapai seseorang, prestasi belajar ditunjukan dengan jumlah nilai raport atau test nilai sumatif. Selain itu pemerintah dan semua pihak yang terlibat diharapkan dapat bekerja sama dalam membangun sumber daya manusia mulai dari pemerintah kota maupun ketentuan otonomi daerah dan kebijakan desentralisasi pendidikan, adanya faktor esternal dan internal dalam dunia pendidikan turut menentukan kualitas dari seorang pendidik ( Sulisworo dkk, 2017:84-86).

Disisi lain kurikulum K13 memiliki tujuan untuk lebih mengedepankan pada student center yaitu siswa sebagai pusat utama dalam pembelajaran dan guru hanya sebatas fasilitator dalam pembelajaran, sehingga siswa dituntut untuk lebih mandiri dalam pemenuhan ilmu pengetahuan baik di sekolah maupun di rumah. Pemenuhan tambahan asupan pelajaran bagi siswa dan dalam rangka mendukung tujuan K13, maka diperlukan adanya menejemen pembelajaran yang dikemas kedalam sebuah sistem yang disebut dengan sistem manajemen pembelajaran atau lebih familiar disebut dengan Learning Management System (LMS). Dengan dukungan teknologi yang semakin maju, LMS telah dirubah ke dalam sistem online sehingga untuk keperluan administrasi, dokumentasi, laporan sebuah kegiatan, kegiatan belajar mengajar sudah dilakukan secara online. Melalui LMS guru dapat mengola kelas dan bertukar infornmasi dengan siswa dan akses terhadap materi pelajaran dalam kurun waktu yang telah ditentukan juga dapat ditentukan. Pendidik sebagai salah satu komponen 
pendidikan mempunyai peran yang cukup besar mengingat posisi dan peranannya terhadap siswa dalam proses pembelajaran di sekolah, maka pendidik dituntut untuk dapat lebih peka terhadap faktor-faktor yang mempengaruhi rendahnya mutu pendidikan pada pembelajaran fisika dilapangan siswa masih menggagap pelajaran yang tidak menarik dan sulit untuk dipahami. Banyak faktor yang melatar belakangi hal tersebut, salah satunya kurangnya motivasi dan minat siswa serta kurangnya variasi terhadap pelakasanaannya

LMS ternyata cukup banyak memberikan kontribusi dari segi pemanfaatan. Fleksibilitas LMS sangat memungkinkan pendidik dan siswa mengaksesnya kapan saja dan dimana saja serta melalui device apa saja (PC, tablet, ataupun smartphone). LMS banyak jenisnya, salah satunya adalah Edmodo. Edmodo merupakan sistem yang sudah siap digunakan. Edmodo memiliki manfaat yang sangat luas sebagai jaringan sosial antara guru dan murid yang dapat dipantau pula oleh orang tua. Apalagi didukung dengan berbagai fitur canggih yang membuat proses belajar mengajar lebih efektif, efisien, dan terorganisir, seperti misalnya fitur polling, gradebook, quiz, file and links, library, assignment, award badge, dan parent code. Namun dari segi bahan ajar ataupun bahan uji pengguna harus mengembangkan sendiri dan mudah diakses siswa. Sehingga dengan adanya pemanfaatan LMS berbasis Edmodo materi fluida dinamis ini diharapkan mampu untuk meningkatkan minat dan prestasi belajar fisika siswa sekolah menengah.

\section{METODE PENELITIAN}

Siswa di MAN 3 Ngawi sebelumnya telah mengenal media pembelajaran digital seperti Microsoft office yang hanya sebatas media pembelajaran namun belum pernah menggunakan sistem pembelajaran Edmodo dalam proses belajar mengajar sehari-hari. Tidak semua siswa dalam satu kelas memiliki notebook atau handphone, sehingga dalam proses penelitian, dilakukan secara kelompok, satu kelompok empat orang dengan satu notebook dan satu handphone digunakan secara bersama-sama. Jika pemberian tugas di rumah menggunakan Edmodo, siswa dapat mengaksesnya melalui sambungan internet pada notebook, handphone atau mendatangi warnet. Penelitian dilaksanakan di MAN 3 Ngawi pada semester ganjil tahun pelajaran 2018/2019. Metode pembelajaran adalah metode ceramah, model pembelajaran adalah model cooperative learning. Jenis penelitian adalah penelitian tindakan kelas (classroom action research). Penelitian tindakan kelas ini dilakukan untuk memecahkan masalah-masalah melalui penerapan langsung di kelas. Subjek penelitian yang digunakan dalam penelitian ini adalah kelas XI MIA 3 dengan jumlah siswa 31 orang. Teknik pengambilan data yang digunakan dalam penelitian ini adalah: observasi, angket minat belajar siswa, dan tes kognitif prestasi belajar siswa. Observasi dan angket minat belajar siswa sebagai analisis data kualitatif, serta tes kognitif hasil belajar siswa sebagai analisis data kuantitatif. Adapun alur dari penelitian tindakan kelas untuk tiap siklus mencakup aktivitas perencanaan, pelaksanaan, observasi, dan refleksi (Arikunto, 2015: 16).

Soal prestasi belajar dan angket minat belajar sebelum diberikan kepada siswa, harus terlebih dahulu ditentukan valid atau tidaknya melalui perhitungan validitas isi yang ditentukan sebelumnya. Kesepakatan ahli fisika sering disebut dengan domain yang diukur menentukan tingkat validitas isi. Validitas diukur melalui indeks validitas, diantaranya indeks yang diusulkan Aiken sebagai berikut:

$$
V=\frac{s}{[m(c-1)]}
$$


dengan $V$ adalah indeks validitas butir; $s$ adalah skor yang ditetapkan pada setiap aspek penilaian butir soal dikurangi skor terendah dalam kategori yang dipakai $s=r-1$ dengan $r$ adalah skor pilihan rater; $S$ adalah total jumlah $s ; m$ adalah banyaknya item; dan $c$ adalah banyaknya kategori yang dipilih oleh rater (Aiken, 1985), $m$ dapat diganti $n$ untuk rater yang lebih dari 1. Nilai indeks validitas berkisar $0-1$. Selain menentukan valid atau tidaknya butir angket dan soal, juga harus ditentukan nilai reliabilitas yang mengacu pada konsistensi pengukuran, yakni bagaimana skor tes/hasil penilaian tetap/tidak berubah dari satu pengukuran ke pengukuran lain. Validitas isi dan reliabilitas dapat ditentukan melalui penilaian guru fisika lain maupun dosen fisika universitas. Soal prestasi belajar dan angket minat belajar dapat diberikan kepada siswa secara berulang-ulang dengan sekali saja menghitung kevalidan dan reliabelnya, namun masih dalam satu materi dan satu perlakuan yang sama.

Reliabilitas dihitung dengan persamaan (Borich dalam Trianto, 2011: 63) sebagai berikut:

$$
\text { Percentage of Agreement }=\left(1-\frac{\mathrm{A}-\mathrm{B}}{\mathrm{A}+\mathrm{B}}\right) \times 100 \%
$$

dengan:
A : penilaian oleh penilai yang bernilai besar
B : penilaian oleh penilai yang bernilai kecil

Instrumen dikatakan baik jika mempunyai koefisien reliabilitas lebih besar atau sama dengan 75\%. Perhitungan reliabilitas dilakukan setelah instrumen digunakan secara empiris yakni digunakan langsung penilai/rater. Setelah soal prestasi belajar dan angket minat belajar valid dan reliabel, maka dapat diberikan kepada siswa yang kemudian dihitung hasil minat dan prestasi belajarnya. Menurut Bintiningtyas dan Lutfi (2016: 138) hasil peningkatan minat dan prestasi belajar siswa kemudian dihitung dengan skor gain :

$$
g=\frac{S_{\text {postest }}-S_{\text {pretest }}}{S_{\max }-S_{\text {pretest }}}
$$

dengan :

$$
\begin{array}{ll}
S_{\text {pretest }} & \text { : Skor pretest (minat sebelum perlakuan) } \\
S_{\text {postest }} & : \text { Skor postest (minat setelah perlakuan) } \\
S_{\max } & : \text { Skor maksimal (minat maksimal) }
\end{array}
$$

Skor gain yang didapatkan, kemudian disesuaikan dengan kriteria.

Tabel 1.Kriteria Skor Gain

\begin{tabular}{cc}
\hline $\mathrm{G}$ & Keterangan \\
\hline $\mathrm{g}>0,7$ & Tinggi \\
\hline $0,3<\mathrm{g} \leq 0,7$ & Sedang \\
\hline $\mathrm{g} \leq 0,3$ & Rendah \\
\hline
\end{tabular}


Mengubah skor rata-rata menjadi skor dengan kriteria diperlukan untuk membuat angket minat belajar siswa. Maka dari data yang mula-mula berupa skor diubah menjadi data kualitatif dengan skala interval. Adapun acuan pengubahan skor menjadi skala tersebut (Sudjana, 2011: 118) dapat dilihat pada tabel 1 berikut ini.

$$
\text { Nilai }=\frac{X}{\Sigma N} \times 100 \%
$$

dengan :

$X \quad$ : Skor yang diperoleh

$\Sigma N \quad$ : Total skor maksimal

Nilai : Nilai kenaikan minat belajar siswa

Tabel 2.Skor Kriteria Angket Minat Belajar

\begin{tabular}{ccc}
\hline Persentase Jawaban (\%) & Nilai Konversi & Kategori \\
\hline $90-100$ & A & Sangat baik \\
$80-89$ & B & Baik \\
$70-79$ & C & Cukup \\
$60-69$ & D & Kurang \\
Kurang dari 60 & E & Tidak baik \\
\hline
\end{tabular}

\section{HASIL DAN PEMBAHASAN}

\subsection{Pembahasan Siklus I}

Siklus I dilakukan selama dua kali pertemuan. Satu minggu dua pertemuan, jadi untuk siklus I dilaksanakan selama satu minggu. Siklus I melaksanakan pembelajaran untuk satu KD (Kompetensi Dasar). Pertama, siswa diperkenankan mengisi angket minat. Pertemuan pertama materi secara singkat diberikan kepada siswa melalui ceramah sampai dengan materi fluida dinamis. Setelah itu pembelajaran dilakukan dengan Edmodo secara berkelompok, sehingga dapat meningkatkan tingkat kerjasama dan hubungan sosial antar teman. Pada siklus I, siswa mencoba membuat akun di Edmodo secara berkelompok dan mengerjakan soal 1-10 secara individu, dengan melihat soal yang dibagikan di dalam Edmodo dan dikerjakan di kertas biasa. Satu kelompok terdiri dari 4 siswa. Setelah siswa mengerjakan soal secara individu, maka dalam satu kelompok harus berdiskusi manakah jawaban yang dianggap benar.

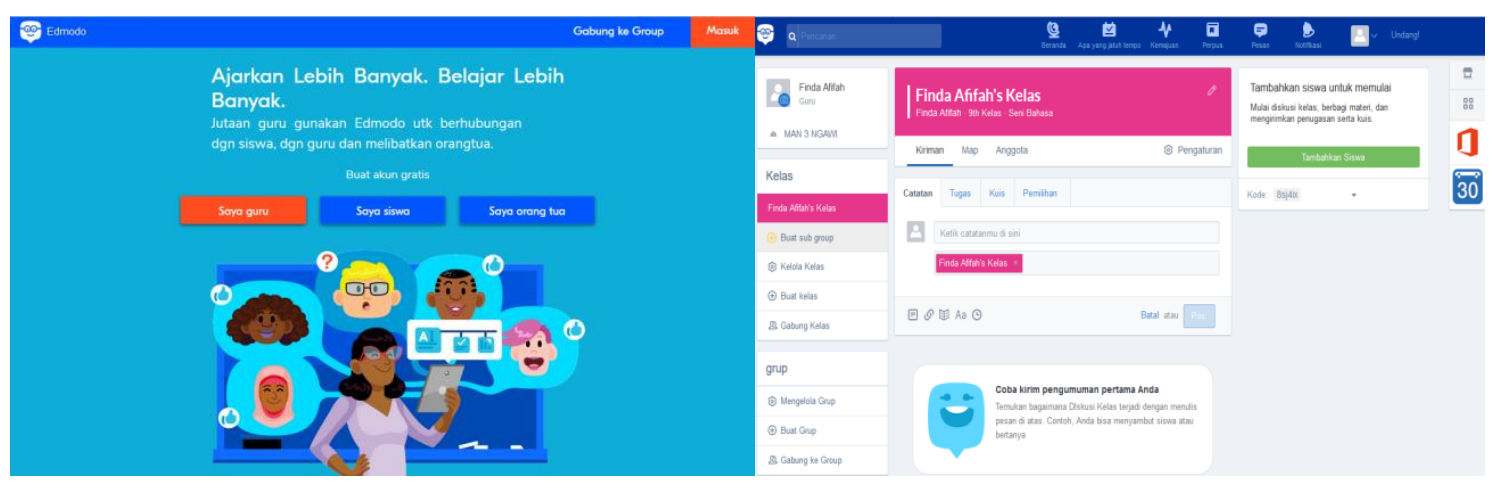

Gambar 1. Tampilan Edmodo 
Setelah berdiskusi, siswa diminta menuliskan jawaban yang benar ke dalam Edmodo dan dikirimkan ke guru Pertemuan kedua pembahasan jawaban yang benar atas soal yang diberikan guru di dalam Edmodo. Berdasarkan hasil analisis dan refleksi pada pembelajaran siklus I, diperoleh hal-hal berikut:

- Siswa masih belum bisa menyelesaikan 10 soal dengan sempurna

- Siswa masih menebak jawaban tanpa mengerti maksudnya dan penerapannya

- Minat belajar siswa sudah meningkat namun masih belum semuanya.

Berdasarkan hasil analisis dan refleksi yang telah dilakukan pada siklus I, maka harus dilakukan perbaikan dan yang akan diterapkan pada siklus II, yaitu :

- Memberikan pemahaman jawaban latihan 1 sampai 10 setelah siswa selesai membahasnya

- Siswa bercerita sedikit mengenai alat-alat yang berhubungan dengan soal latihan, agar pemahaman siswa terhadap penerapan fluida dinamis bertambah

- Memberikan motivasi kepada siswa agar minat juga bertambah

- Memberikan arahan kepada siswa dalam penggunaan Edmodo dalam melihat materi atau mengerjakan soal

\subsection{Pembahasan Siklus II}

Pembelajaran pada siklus II ini pada umumnya sama dengan siklus I. Namun, siswa sudah mulai terbiasa dengan pembelajaran yang dilaksanakan, sehingga guru lebih mudah untuk mengarahkan siswa. Pertemuan pertama melanjutkan materi yaitu penjelasan secara singkat mengenai fluida dinamis dan penerapannya. Setelah itu, pembahasan kembali jawaban soal latihan 1-10 dan siswa secara berkelompok dan menganalisis alat-alat dan penerapan fluida dinamis yang terdapat dalam soal. Suasana kelas terkesan lebih hidup saat kelompok bercerita mengenai penerapan fluida dinamis tersebut. Pertemuan kedua mengerjakan soal latihan11-20 dan siswa mengisi angket minat belajar. Melalui hasil tes kognitif Siklus II, umumnya siswa sudah dapat menjawab soal yang diberikan dengan benar. Hal ini menunjukkan bahwa siswa telah dapat memahami materi yang diberikan, serta hasil tes kognitif meningkat menjadi 93 dan telah memenuhi kriteria ketuntasan minimal/KKM sebesar 75. Minat belajar siswa juga telah meningkat menjadi 87,5\% dari sebelumnya sebesar $70 \%$. Berdasarkan komentar siswa yang dituliskan pada kolom komentar dan saran pada angket, dapat disimpulkan bahwa sebagian besar siswa merasa senang dengan pembelajaran yang diterapkan. Melalui Edmodo dengan bimbingan guru, maka siswa lebih aktif dan berminat untuk belajar fisika. Selain itu, melalui pengerjaan soal latihan secara kelompok dan dibahas oleh guru, siswa lebih memahami materi dan penerapannya dalam kehidupan sehari-hari.

Tabel 3.Minat Belajar Siswa

\begin{tabular}{cc}
\hline Sebelum & Sesudah \\
\hline $70 \%$ & $87,5 \%$ \\
\hline
\end{tabular}

Tabel 4.Nilai Rata-Rata Prestasi Belajar Siswa

\begin{tabular}{cccc}
\hline \multicolumn{2}{c}{ Siklus I } & \multicolumn{2}{c}{ Siklus II } \\
\hline pretest & postest & pretest & postest \\
\hline 50 & 78 & 80 & 93 \\
\hline
\end{tabular}


Tabel 5.Nilai N-GAIN Minat dan Prestasi Belajar Siswa

\begin{tabular}{ccc}
\hline \multirow{2}{*}{ Minat Belajar } & \multicolumn{2}{c}{ Prestasi Belajar } \\
\cline { 2 - 3 } & Siklus I & Siklus II \\
\hline 0,324 (sedang) & 0,48 (sedang) & 0,61 (sedang) \\
\hline
\end{tabular}

\section{PENUTUP}

\subsection{Simpulan :}

Berdasarkan hasil penelitian dan pembahasan yang telah diuraikan, dapat diambil simpulan sebagai berikut:

1. Siklus I diperoleh rata-rata minat siswa $70 \%$ dan nilai rata-rata tes 78 . Siklus II diperoleh rata-rata minat siswa $87,5 \%$ dan nilai rata-rata tes $93 . \mathrm{N}-$ Gain hasil belajar siklus I sebesar 0,48 (sedang) dan siklus II sebesar 0,61 (sedang). Sedangkan N-Gain minat belajar sebesar 0,324 (sedang).

2. Pemanfaatan LMS berbasis Edmodo materi fluida dinamis dapat meningkatkan minat dan prestasi belajar fisika siswa sekolah menengah

\subsection{Saran :}

1. Bagi Guru

Guru diharapkan dapat memanfaatkan LMS berbasis Edmodo dalam materi berbeda, di kelas berbeda, dan pada soal latihan berbeda dalam proses pembelajaran fisika.

2. Bagi Sekolah

Hasil penelitian ini hendaknya dapat dipergunakan sebagai masukan dan pertimbangan bagi sekolah untuk menerapkan strategi pembelajaran baru agar dapat meningkatkan minat dan prestasi belajar siswa.

\section{DAFTAR PUSTAKA}

Aiken, L. R. (1985). Three Coefficient For Analyzing The Reliability And Validity Of Ratings. Educational and Psychological Measurement, 45, 131-142. http://journals.sagepub.com/doi/10.1177/0013164485451012

Anwar. Saifuddin. 2005. Penelitian Tindakan Kelas. Jakarta: PT Bumi Aksara.

Arikunto, S. 2015. Penelitian Tindakan Kelas. Jakarta: PT Bumi Aksara.

Nita Bintiningtyas \& Achmad Lutfi. (2016). Pengembangan Permainan Varmintz Chemistry Sebagai Media Pembelajaran pada Materi Sistem Periodik Unsur. Unesa Journal of Chemical Education, 5(2), http://ejournal.unesa.ac.id/index.php/journal-ofchemicaleducation/article/view

Slameto. (2010). Belajar dan Faktor-Faktor yang Mempengaruhinya. Jakarta: PT Rineka Cipta.

Sudjana N. (2011). Penilaian Hasil Proses Belajar Mengajar. Bandung: Remaja Rosdakarya.

Sulisworo D. (2016). The Contribution of Education System Quality to Improve the Nation's Competitiveness of Indonesia. Journal of Education and Learning, 10, 127-138, https://www.researchgate.net/publication/307644413_The_Contribution_of_the_Edu cation_System_Quality_to_Improve_the_Nation's_Competitiveness_of_Indonesia 
Sulisworo. D, Nasir \& Maryani. (2017). Identification of Teacher's Problems in Indonesia on Facing Global Community. International Journal of Research Studies in Education, 6(2),

https://www.researchgate.net/publication/305763396_Identification_of_teachers'_pro blems_in_Indonesia_on_facing_global_community

Sulisworo. D, Ishafit \& Firdausy K. (2016). The Development of Mobile Learning Application using Jigsaw Technique. International Journal of Interactive Mobile Technologies, 10(3),http://online-journals.org/index.php/i-jim/article/view/5268/4026

Trianto. 2010. Pengantar Penelitian Pendidikan Bagi Pengembangan Profesi Pendidikan dan Tenaga Kependidikan. Jakarta: Kencana Prenada Media Group. 